\title{
MÁrio de ANDRAde e Adorno: CARTAS, PREFÁCIOS E "O ENSAIO COMO FORMA"
}

\author{
Jakeline Fernandes Cunha*
}

\section{Resumo}

O objetivo do artigo será fazer uma aproximação entre os escritos dispersos de Mário de Andrade com "O ensaio como forma" de Adorno. Consideraremos que o Mário das cartas e, especialmente, o Mário dos dois prefácios esboçados para Macunaima, escreve experimentando, intuindo, raciocinando e questionando.

\section{Abstract}

The aim of this article is to make an approximation between Mario de Andrade's disperse writings and Adorno's work "The Essay as Form". The assumption is that Mario de Andrade, both in the letters he wrote and in the two prefaces he sketched for Macunaíma, was a writer who made experiments, had intuitions, built reasonings and proposed discussions.
Palavras-chave

Epistolografia, prefácios, ensaio, Mário de Andrade, Theodor W. Adorno.

Keywords

Epistolography, prefaces, essay, Mário de

Andrade, Theodor $\mathrm{W}$. Adorno.

* Mestranda em Teoria Literária pela Universidade de São Paulo. 


\title{
"O ensaio como forma" na experiência da carta
}

\author{
A
} Manuel Bandeira no Rio de Janeiro e Joaquim Inojosa no Recife. Ao acompanhar a liberdade de espírito (tal como aquela pregada por Adorno em "O ensaio como forma”) e, assim, as mudanças estéticas do modernismo, as cartas trocadas entre esses estudiosos perdem a formalidade, já que substituem efetivamente a conversa face a face, de acordo com Júlio Castãnon Guimarães. Esta modificação, sem dúvida, segundo o autor, "propicia um maior desembaraço, de modo que, para além de questões literárias, a carta [no modernismo] será também espaço de manifestações pessoais, de informações privadas de pessoas envolvidas na vida literária". ${ }^{1}$ Devido à importância como escritor que atuou em múltiplas áreas (poesia, ficção, crítica de literatura, de artes plásticas e de música), devido ao seu "gigantismo epistolar" e por ter se correspondido com os principais intelectuais da época, Mário de Andrade é a figura principal em termos de correspondência literária no modernismo brasileiro.

A epistolografia, sobretudo entendida como "rede textual" e como construção de uma "história" é um gênero espontâneo, fragmentário e híbrido, invadido por

${ }^{1}$ GUIMARÃES, Júlio Castañon. Contrapontos: notas sobre correspondência no modernismo. Rio de Janeiro: Fundação Casa de Rui Barbosa/Ministério da Cultura, 2004, p. 24. (Coleção Papéis Avulsos, 47)

2 Jeanne Bem distingue carta de correspondência: "a carta é pontual, o autor da carta jamais vai além dela, vinculando-a no máximo à sua carta anterior e a do correspondente a quem responde. A correspondência é uma passagem do pontual à totalidade e à duração. A carta é um fragmento de texto flutuando. A correspondência lhe dá ancoragem, ela transforma a sucessão das cartas em uma história e se constitui em rede textual". O organizador que dá, portanto, dimensão pública às cartas: é ele que constrói essa "história", essa "rede textual". In: O Estatuto Literário da Carta. Tradução de Cláudio Hiro. Gênese: Revué Internationale de Critique Génétique, Paris, n. 13, p. 104, 1999. 
outras instâncias de criação. Neste sentido, a correspondência ou a carta pode se transformar em autobiografia, em crônica, em diário, em romance, ${ }^{3}$ em elemento ficcional, em narrativa epistolar e, sobretudo, em ensaísmo. É nesse âmbito que para Mário de Andrade a carta é o lugar de experimento, de adestramento, de memória, de conhecimento ou esforço de criação e, assim, o lugar da reflexão sobre o fazer literário, o lugar, enfim, de interação entre a sua vida e suas ações no plano cultural.

Podemos pensar as correspondências (incluindo os dois prefácios de Macunaíma, quase cartas-ensaio) como um arquivo de ideias, técnicas e ideários vanguardistas e como um "arquivo de criação", ${ }^{4}$ que proporciona buscar a gênese e as várias etapas de elaboração de uma obra artística, como da rapsódia de Mário de Andrade. Pensar assim é refletir a relação da carta com a crítica, com o exercício ensaístico que ao experimentar, avaliar, inventar, "instaura hesitação", "incita reações", "aprofunda temas e assuntos diversos" e problematiza definições. ${ }^{5}$ Essa aproximação

não se dá apenas por referência, [...], mas na quase totalidade das cartas pelo fato de o texto destas vir a discorrer sobre os assuntos de interesse dos correspondentes. Em alguns casos mais extremos, a carta se confunde inteiramente com um texto ensaístico. ${ }^{6}$

Evidentemente para que esse exercício crítico seja rico e dinâmico, os interlocutores como Mário e Bandeira, cuja amizade epistolar durou mais de duas décadas, mantêm um "pacto" determinado no início da correspondência. Esse contrato longo, iniciado em 1922, manifesta o movimento vivo do pensamento de Mário movido pelo debate continuum.

$\mathrm{Na}$ ação compartilhada de cartas perdura o diálogo aberto e didático da crítica de Mário de Andrade, capaz de interferir na opinião e na produção dos seus destinatários. Mário, para seduzir os jovens escritores, cria artifícios facilitadores, como comparações e distinções de formulações para o mesmo tema, bem como a estratégia do apelo e não do conselho (pois esse pressupõe superioridade, poder,

\footnotetext{
${ }^{3}$ Manuel Bandeira, na célebre carta enviada a Mário de Andrade em 8 de abril de 1933, faz o seguinte comentário ao dizer que está organizando seus papéis, como as cartas: "Como li cartas de minha gente de mistura com a correspondência de amigos (você, Couto e outros), tudo muito rico de substância humana, tenho a impressão de ter lido um romance do tipo Contraponto de Huxley ou do Mannhattan transfer do Dos Passos". Esse comentário abre "perspectivas para se trilhar a correspondência de Mário e Bandeira como um 'romance'. Esse diálogo epistolar forja um espaço ficcional privilegiado para onde convergem personagens, situações, confrontos e ambiência histórica abarcando mais de duas décadas". MORAES, Marcos Antonio (Org.). Correspondência de Mário de Andrade $\mathcal{E}$ Manuel Bandeira. 2. ed. São Paulo: Editora da Universidade de São Paulo/Instituto de Estudos Brasileiros, 2001, p. 556-63. (Coleção de Correspondência de Mário de Andrade, 1)

${ }^{4}$ MORAES, Marcos Antonio. Epistolografia e crítica genética. Revista Ciências e Cultura, Campinas, v. 59, n.1, p. 30-2, 2007.

${ }^{5}$ Ibid., p. 17

${ }^{6}$ GUIMARÃES, Júlio Castañon. Contrapontos: notas sobre correspondência no modernismo. Rio de Janeiro: Fundação Casa de Rui Barbosa/Ministério da Cultura, 2004, p. 32. (Coleção Papéis Avulsos, 47) (grifos nossos)
} 
e não expressão de igualdade $)^{7}$ para que eles o acompanhem e difundam suas ideias. Por meio da epistolografia, o autor coloca em prática uma arte heurística, i.e., aquela que consiste em fazer descobrir pelo aluno o que lhe quer ensinar.

As cartas-ensaio são, portanto, como um palco da experiência intelectual desse grande autor. Nesse palco observamos que o seu "pensamento não avança em sentido único, em vez disso, os vários momentos se entrelaçam como um tapete", para usar a metáfora adorniana. ${ }^{8}$ A construção do projeto nacionalista de Mário evidencia a densidade dessa tessitura tateante que não é invariável no tempo.

\section{O nacionalismo em pedaços luminosos de cartas-ensaio}

Vimos na seção anterior que, devido ao caráter essencialmente movediço das cartas, são muitos caminhos e leituras que se podem buscar no seu estudo. Podemos tomar, por exemplo, fragmentos de cartas como um ensaio. Os seus pequenos pedaços minam e iluminam uma ampla discussão sobre o projeto nacionalista de Mário de Andrade, amadurecido no ano de 1924 - primeiro momento da sua pedagogia epistolar quando, pelo esforço do convencimento, buscava seduzir seus interlocutores, moços "em formação". Vale esclarecer que pensamos em fragmentos (de cartas, prefácios) porque o ensaio, segundo Adorno, "pensa em fragmentos, uma vez que a própria realidade é fragmentada; ele encontra sua unidade ao buscá-la através das fraturas, e não ao aplainar a realidade fraturada". ${ }^{9}$

$\mathrm{Na}$ modulação do nacionalismo, "Mário tenta elaborar e desenvolver uma caracterização do particular sem cair no exotismo. Nesse momento, a pedagogia epistolar de Mário de Andrade fixa fronteiras da sua concepção de nacionalismo, problematizando-o". ${ }^{10}$ Essa tentativa de análise e conhecimento sobre o Brasil, iniciada mais especificamente no final de 1924 e começo de 1925, foi bastante divulgada pelo autor de Macunaíma entre seus colegas de geração, como em correspondências para Carlos Drummond de Andrade, Joaquim Inojosa e Manuel Bandeira.

A resposta de Mário em 10 de novembro de 1924 ao jovem poeta Drummond dá a medida de sua visão amadurecida perante a vida cultural brasileira: um "monstro mole e indeciso". Nessa missiva, Mário para demonstrar o equívoco do recente amigo - atraído pela "Moléstia de Nabuco"11 - expõe uma concepção de naciona-

\footnotetext{
${ }^{7}$ Sobretudo no capítulo "Orgulho de jamais aconselhar", Marcos Antonio de Moraes explica com maestria essa atitude humanista e pedagógica de Mário de Andrade no seu exercício epistolar.

${ }^{8}$ ADORNO, Theodor W. "O ensaio como forma". In: Notas de Literatura I. Tradução de Jorge de Almeida. São Paulo: Duas Cidades, 2003, p 30.

${ }^{9}$ Ibid., p. 35.

${ }^{10}$ MORAES, Marcos Antonio. "Abrasileirar o Brasil" (Arte e literatura na epistolografia de Mário de Andrade). Caravelle (Cahiers du Monde Hispanique et Luso-Bresilien), Toulouse, n. 80, p. 41, 2003.

${ }^{11}$ Em carta de 22 de novembro desse mesmo ano, Drummond lastima o seu próprio "nascer entre paisagens incultas e sob céus pouco civilizados": "detesto o Brasil como a um ambiente nocivo à expansão do meu espírito. Sou hereditariamente europeu”. FROTA, Lélia Coelho (Org.). Carlos E Mário: correspondência completa entre Carlos Drummond de Andrade (inédita) e Mário de Andrade. Prefácio e notas de Silviano Santiago. Rio de Janeiro: Bem-te-vi, 2002, p. 59-51.
} 
lismo articulando suposições, que podemos enxergar como sedutoras, entre o modo de exercitar a vida e o intelectual. Antes de tudo, explica Mário, era preciso gostar de "viver com religião a vida", gostar de viver a "verdade da vida", ou seja, viver tudo, viver todas as experiências e manifestações dela, sem indiferenças ou preconceitos. Para o autor paulistano é com a "gente chamada baixa e ignorante" que se "aprende a sentir" "o espírito religioso da vida". Isso não significa, no entanto, atacar e negar "a erudição e a civilização", "ao contrário respeito-as e cá tenho também as minhas fichinhas de leitura" - tão significativas, como se sabe, para a construção de Macunaíma. ${ }^{12}$ Mário aclara a Drummond que a via de acesso ao nacional está na abertura para o cotidiano, para a cultura popular, e isso não quer dizer esquecimento do conhecimento livresco e erudito, considerado por ele como uma ferramenta ou manancial de informações.

O pernambucano Joaquim Inojosa também recebeu de Mário uma carta em 28 de novembro de 1924, cujo apelo é também a necessidade de "abrasileiramento do brasileiro". Entretanto abrasileirar o brasileiro "não quer dizer regionalismo nem mesmo nacionalismo = o Brasil para os brasileiros". O Brasil "pra ser civilizado artisticamente, entrar no concerto das nações" precisa contribuir "com a sua parte pessoal, com o que singulariza e individualiza, parte essa única que poderá enriquecer e alargar a civilização". Para convencer seu interlocutor, Mário, nessa exposição, compara o lado prático e o lado artístico do nacionalismo. Se o Brasil candidatar-se a colaborar "para organização econômica da Terra" teríamos que fornecer não ingredientes secundários, subversivos e inúteis como o "trigo próprio da Rússia ou o vinho próprio da França ou da Itália", e sim ingredientes "específicos da nossa terra", os quais podem "alargar e engrandecer a economia humana": a "borracha, o açúcar e o café e a carne". ${ }^{13}$ Do mesmo modo,

nós teremos nosso lugar na civilização artística humana no dia em que concorrermos com o contingente brasileiro, derivado das nossas necessidades, da nossa formação por meio da nossa mistura racial transformada e recriada pela terra e clima pro concerto dos homens terrestres. ${ }^{14}$

Em carta de 1925 a Manuel Bandeira, Mário, contrariado com a semelhança de sua concepção de nacionalismo com a de Graça Aranha ("porque não me lembro de ter falado pra ele ou pra mesa sobre essa ideia de que é só sendo brasileiro que nos universalizaremos"), diz a "Manu" "meio complicadamente" sobre sua ideia de nacionalismo, desejando na verdade lembrar as palavras escritas antes em carta a Inojosa (referida acima) em 28 de novembro de 1924, como deixa ver o fragmento a seguir:

${ }^{12}$ Ibid., p. 46, 48 e 56.

${ }^{13}$ INOJOSA, Joaquim. O movimento modernista em Pernambuco. Rio de Janeiro: Guanabara, 1968, p. 340-1.

${ }^{14}$ Ibid., p. 341. 
minha ideia exata é que é só sendo brasileiros, isto é, adquirindo uma personalidade racial e patriótica (sentido físico) brasileira que nos universalizaremos, pois que então concorremos com um contingente novo, nova assemblage de caracteres psíquicos pro enriquecimento do universal humano. ${ }^{15}$

O conteúdo dos fragmentos, discutido nas missivas acima por Mário, parece desenvolver-se segundo o processo do ensaio explicado por Adorno. Tal como a forma adorniana da tentativa que se estrutura como se pudesse a qualquer momento ser interrompida, assim também é a construção obstinada do projeto nacionalista de Mário, tecido sempre e continuamente na interação epistolar. Esse projeto é fruto de várias intuições, insights que vão se desdobrando em um conceito crítico cristalizado por seu próprio movimento. Desse processo de produção conceitual - e artístico, no caso das obras - faz parte a cumplicidade, o aval, a afinidade literária, a participação e o diálogo dos interlocutores de Mário, que passam por uma verdadeira indagação socrática. Seu "conceito" de nacionalismo, em muitos momentos, surge então da relação dos sujeitos missivistas com o objeto singular, o Brasil, sem a pretensão de totalidade ou esgotamento do tema. A interpretação que Adorno faz do ensaio, forma crítica por excelência, diz ele, aproxima muito do Mário missivista, que "absorve conceitos e experiências externas [...] absorve teorias", como as vanguardistas, "só que a sua relação com elas não é uma relação" ingênua - maiormente depois da primeira fase do Modernismo. ${ }^{16}$

Escrever cartas-ensaio foi um processo decisivo para construção do conceito de brasilidade do autor modernista: mesmo que Mário não percebesse do ponto de vista teórico "a capacidade" do ensaio "de dar voz ao conjunto de elementos do objeto" - e daí o fato de se aproximar de uma "autonomia estética" ainda que diversa da arte ${ }^{17}$ - alargou suas ideias sobre o país apoiado nessa forma profunda, só depois sistematizada por Adorno. O fragmento, a seguir, de carta datada de 15 de novembro de 1923 a Tarsila, que se encontrava em Paris, elucida o posicionamento nacionalista de Mário mais próximo da forma linear e exótica à forma crítica e densa moldada a partir do final de 1924 em carta, por exemplo, a Joaquim Inojosa. Em tom espirituoso o autor conclama a amiga:

Abandona Paris! Tarsila! Tarsila! Vem para a mata-virgem, onde não há arte negra, onde não há também arroios gentis. HÁ MATA VIRGEM. Criei o matavirginismo. Disso é que o mundo, a arte, o Brasil e minha queridíssima Tarsila precisam. ${ }^{18}$

${ }^{15}$ MORAES, Marcos Antonio (Org.). Correspondência de Mário de Andrade E Manuel Bandeira. 2. ed. São Paulo: Editora da Universidade de São Paulo/Instituto de Estudos Brasileiros, 2001, p. 218. (Coleção de Correspondência de Mário de Andrade, 1)

${ }^{16}$ ADORNO, Theodor W. O ensaio como forma. In: Notas de Literatura I. Tradução de Jorge de Almeida. São Paulo: Duas Cidades, 2003, p. 35.

${ }^{17}$ Ibid., p. 18.

${ }^{18}$ AMARAL, Aracy. (Org.). Correspondência Mário de Andrade e Tarsila do Amaral. São Paulo: Editora da Universidade de São Paulo: Instituto de Estudos Brasileiros, Universidade de São Paulo, 2001, p. 79. (Coleção de Correspondência de Mário de Andrade, 2) 
Nota-se que um ano depois dessa carta a pintora do quadro Abaporu, o conceito do autor ganha forma ondulante e variada. Os fragmentos destacados das cartas a Drummond, a Inojosa e a Bandeira denotam certa diversificação das ideias do autor que vão se multiplicando e relativizando.

Mário de Andrade, especialmente por meio das missivas, molda no final de 1924 um conceito crítico e sinuoso de nacionalismo que

[...] passava pela caracterização de um projeto artístico que visava à avaliação crítica das ideias importadas, à busca das raízes culturais e, a partir disso, a projeção de um núcleo civilizatório "no concerto das nações", a universalidade através do traço que 'singulariza e individualiza'. ${ }^{19}$

Os fragmentos de cartas destacados e essa afirmação de Marcos Antonio de Moraes nos revelam, portanto, que o autor elaborou aos poucos uma expressão "tipo ao mesmo tempo local e universal", "reencontrando a influência europeia por um mergulho no detalhe brasileiro". ${ }^{20}$ Essa concepção móbil e dialética de nacionalismo desenvolvida por Mário de Andrade nas cartas e, sobretudo, adjacente a um diálogo com jovens escritores, será "corpo e alma" de Macunaíma em 1928. O que era certa teorização nas cartas torna-se exercício experimental na ação rapsódica/romanesca. Aspecto importante que de antemão expressa a diferença entre a experiência do fazer romance com a do fazer epistolográfico.

\section{"O ensaio como forma" e os prefácios de Macunaíma}

O Mário das cartas, o Mário que formulou e renunciou os prefácios para $\mathrm{Ma}$ cunaíma - que, aliás, lembram muito as discussões que aparecem nas suas epístolas quando fala da obra - escreve com a mesma "descontinuidade" "essencial ao ensaio", cujo "assunto é sempre um conflito em suspensão". ${ }^{21} \mathrm{O}$ caráter impreciso dessa forma adorniana não quer dizer, entretanto, que se trate de algo vago: o ensaio é "mais aberto", devido a sua própria disposição de antissistemático e, concomitantemente, é "mais fechado", por trabalhar enfaticamente na forma da apresentação ou "exposição". ${ }^{22}$ Os prefácios que comporiam a abertura de Macunaíma, um escrito em 19 de dezembro de 1926 e o outro em 27 de março de 1928, são, portanto, memórias-rascunho muito próximas das cartas-ensaio. ${ }^{23}$

${ }^{19}$ MORAES, Marcos Antonio. "Abrasileirar o Brasil" (Arte e literatura na epistolografia de Mário de Andrade). Caravelle (Cahiers du Monde Hispanique et Luso-Bresilien), Toulouse, n. 80, p. 46, 2003. (grifos nossos)

${ }^{20}$ CANDIDO, Antonio. Literatura e Sociedade. São Paulo: Companhia Editora Nacional, 1985, p. 121 .

${ }^{21}$ ADORNO, Theodor W. O ensaio como forma. In: Notas de Literatura I. Tradução de Jorge de Almeida. São Paulo: Duas Cidades, 2003, p. 35. A partir de agora essa citação será mencionada como A.

${ }^{22}$ A, p. 30.

23 Os manuscritos dos dois prefácios que Mário esboça para a obra (e decide manter inéditos até 1972) tiveram um curioso destino. Eles foram confidenciados a Alceu Amoroso Lima em 19 de maio de 1928: Mário envia ao amigo uma cópia dos dois prefácios e uma carta que além de infor- 
Esses dois escritos, em afinidade com uma experiência intelectual mais aberta, parecem revelar que há na composição da própria rapsódia ostensivos traços d' "O ensaio como forma".

Pensar os prefácios renegados por Mario é pensar n' "O ensaio como forma" de Adorno, produto misto de características intuitivas (espontaneidade da imaginação subjetiva) e racionais (pensamento conceitual e de teor especulativo). Mário, no segundo prefácio, ao descrever sobre as intenções e problemas do livro, que careciam explicar, parece evidenciar que opera pelo método de tentativa e erro, ${ }^{24} \mathrm{em}$ virtude da abertura essencial da experiência - que é intermediada pela história, pois, segundo Adorno, a experiência "meramente individual, que a consciência toma como ponto de partida por sua proximidade, é ela mesma já mediada pela experiência mais abrangente da humanidade histórica". ${ }^{25}$

mar a decisão de não publicá-los explica impressões de sua obra de arte. José de Paula Ramos Júnior salienta que esse escritor e líder católico - assinando com pseudônimo de Tristão de Ataíde aproveita parcialmente da carta e dos prefácios para elaborar a primeira crítica publicada da obra, já que a primeiríssima recepção "afigura-se como depoimento crítico mascarado". Sobre essa instigante recepção inaugural, Ramos Júnior, apoiado nas hipóteses já levantadas por Silviano Santiago, procura ratificar que o resenhista anônimo da matéria intitulada Macunaíma: O livro de Mário de Andrade, publicada no Diário Nacional em 07 de agosto de 1928, é o próprio autor de Macunaíma. Os prefácios enviados a Tristão de Ataíde foram copiados a mão ou escritos na máquina datilográfica "Manuela"? José de Paula Ramos destaca que naquela epístola endereçada a Alceu Amoroso Lima (em 19 de maio de 1928) Mário anunciara que enviaria os originais 'num manuscrito terrível e a lápis'. Deve-se levar em conta também que o próprio "Tristão assinala, na sua recepção à rapsódia, que tinha 'em mãos [...] os originais desses dois prefácios" (p. 190). Os manuscritos, escritos a mão, teriam sido devolvidos posteriormente a Mário de Andrade. In: A fortuna crítica de Macunaima: Primeira onda (1928-1936), 2006, p. 21. Dissertação de doutorado - Departamento de Letras Clássicas e Vernáculas/Faculdade de Filosofia, Letras e Ciências Humanas, Universidade de São Paulo.

${ }^{24}$ Ramos Júnior ao trabalhar as noções mariodeandradianas, como a de primitivismo e obra de circunstância (escolha essa que requer sacrifício da perenidade), afirma que Mário "assume no experimentalismo artístico assumido" a "consciência de que, nessa linha, poderia errar e erraria muito. Desse modo, Mário "concebe o erro não só como inevitável no processo, mas, sob a perspectiva do pragmatismo ético-estético, até mesmo como algo que pode ser voluntariamente acolhido no artefazer comprometido com as necessidades históricas (sobretudo sociais e culturais) do país, deduzidas de premissas documentadas e criticamente analisadas (2006, p. 175). (grifos nossos)

${ }^{25}$ A, p. 26. Mário de Andrade, como se sabe, consciente da linguagem literária "não admite o simplório método de registro bruto da realidade", que devia ser subordinado ou "dar-se dentro dela", diz Lafetá em 1930: A crítica e o Modernismo (2000, p. 219-20.). A elaboração de Macunaíma - tal como revela Gilda de Mello e Souza em O tupi e alaúde - não cimentada na mímesis, mas no processo de compor do folclore musical, confirma essa postura do crítico uspiano. Mário exercita em Macunaíma, nos termos de João Luiz Lafetá, o "conceito da 'técnica pessoal', baseado na pesquisa incessante do material e na confrontação das questões essenciais de seu tempo". O autor modernista, com isso, intui o "verdadeiro engajamento da forma" (2000, p. 222-3). Intuição, como se sabe, legitimada sob o ponto de vista teórico, mais tarde, por Antonio Candido: os elementos extraliterários tornam força atuante e inerente à construção da obra de arte, i.e., são reduzidos estruturalmente em fatores estéticos. Em $O$ tupi e o alaúde, a mediação histórica está evidente na noção de respeito ao material pré-constituído com que Mário opera, sem pressupor subserviência nem apagamento da intencionalidade expressiva. 
Essa forma da tentativa encarada como o "ideal utópico de acertar na mosca" mesclada com "a consciência da própria falibilidade e transitoriedade" 26 é percebida e revelada por Mário de Andrade nesse fragmento do prefácio de 1928:

Este livro de pura brincadeira escrito na primeira redação em seis dias ininterruptos de rede, cigarros e cigarros na chácara de Pio Lourenço perto do ninho da luz que é Araraquara, afinal resolvi dar sem mais preocupação (...). Não me amolo que sejam péssimas e mesmo que minha obra toda tenha a transitoriedade precária da minha vida. O que me interessa mesmo é dar pra mim o destino que as minhas possibilidades me davam. É que tenho sido útil: as preocupações, as tentativas, as amizades e até as repulsas (...) que tenho despertado provam bem. $(\ldots)^{27}$

No início desse depoimento observamos que a criação de Macunaíma, tal como o pensamento de Adorno, evoca liberdade, uma vez que a "felicidade e jogo lhe são essenciais". Mário deixa claro nesse prefácio, como no outro de 1926, que o livro de férias escrito no meio de mangas, abacaxis e cigarros de Araraquara, um brinquedo "não começa com Adão e Eva", "como uma criação a partir do nada", mesmo porque é resultado de muita peleja, diz no início do primeiro manuscrito, muita pesquisa anotada nas fichinhas. O parto de uma obra de estrutura deliberadamente ambígua, como Macunaíma, pressupõe a lição de começar "com aquilo o que deseja falar" e terminar "onde sente ter chegado ao fim", onde lhe prouver, onde julgar que seus objetivos se encontram satisfeitos, "não onde nada resta a dizer". ${ }^{28}$ A tensão não resolvida da rapsódia floresce daí. No término de um dos prefácios, Mário de Andrade enfatiza que "nas épocas de transição social como a de agora é duro o compromisso com o que tem de vir e quase ninguém sabe. Eu não sei. [...]. O presente é uma neblina vasta. [...]. Se trata duma verdadeira impossibilidade. [...]". Vê-se aí o aspecto sem compromisso do livro na qual evita de "tirar dele uma fábula normativa". ${ }^{29}$

Mário de Andrade, como escritor recalcitrante à exatidão analítica, reserva aos seus escritos "um lugar entre os despropósitos", já que estão longe daquilo que agrada o pensamento tradicional rígido. ${ }^{30}$ A gestação de Macunaíma - obra de arte, arte de circunstância/ação - supõe uma organização, uma técnica e um domínio exploratório de ideias que a torna autônoma, próxima do espírito ensaístico adorniano. Afinal escreve ensaisticamente

quem compõe experimentando; quem vira e revira o seu objeto, quem o questiona e o apalpa, quem o prova e o submete à reflexão; quem o ataca de diversos lados e reúne no olhar de seu

\footnotetext{
${ }^{26}$ A, p. 35.

${ }^{27}$ LOPEZ, Telê Ancona. Macunaíma: a margem e o texto. São Paulo: HUCITEC, 1974, p. 90.

${ }^{28}$ A, p. 17.

${ }^{29}$ LOPEZ, Telê Ancona. Macunaíma: a margem e o texto. São Paulo: HUCITEC, 1974, p. 92-3.

${ }^{30} \mathrm{~A}$, p. 17.
} 
espírito aquilo que vê, pondo em palavras o que o objeto permite vislumbrar sob as condições geradas pelo ato de escrever. ${ }^{31}$

A construção de Macunaíma, comparada por Gilda de Mello Souza à elaboração do folclore musical, é, assim, análoga no plano da arte à forma ensaio, uma vez que exemplifica uma experiência intelectual de um aprendiz que, imbuído na liberdade de criar artisticamente, bota "em palavras o que o objeto permite vislumbrar sob as condições geradas pelo ato de escrever". Com isso Macunaíma é "profundo por se aprofundar em seu objeto e não pela profundidade com que é capaz de reduzi-lo a outra coisa". ${ }^{32}$ Esse tipo de pensamento (negado por alguns críticos como vai pontuar Gilda de Mello, em $O$ tupi e o alaúde, em relação a Haroldo de Campos) "adquire sua profundidade em função do seu grau de penetração nas coisas, e não na profundidade da relação que ele estabelece entre elas e algo diferente das mesmas", diz Rodrigo Duarte explicando Adorno. ${ }^{33}$ Mais uma vez a rapsódia

não passou dum jeito pensativo e gosado de descansar umas férias relumeante de pesquisas e intenções, muitas das quais só se tornaram conscientes no nascer da escrita, me parece que vale um bocado (...) me parece que vale um bocado como sintoma de cultura brasileira. ${ }^{34}$

Os dois prefácios de Macunaíma nos instigam, enfim, a refletir sobre esse livro "déroutante" que apesar de ser fruto de "pesquisas e intenções", nasceu de uma tentativa, de uma deliciosa brincadeira. Uma brincadeira, portanto, intelectual, séria, individual e artística, cujo processo de criação se sintoniza bastante à lição de Adorno. O resultado dessa tessitura ensaística, análoga a priori à elaboração da música do cantador nordestino, é, no entanto, algo único e invencível.

Lembra-se que a "contradição insolúvel", 35 "a tensão que se faz constitutiva em todos os níveis" e o "cruzamento de conotação e metalinguagem" na rapsódia/ romance transformam-na, em "termos althusserianos", na "pergunta da pergunta", no "questionamento do questionamento". ${ }^{36}$ Com isso quando refletimos sobre o

${ }^{31}$ A, p. 35-6.

${ }^{32}$ A, p. 27.

${ }^{33}$ DUARTE, Rodrigo. A ensaística de Theodor W. Adorno. Adornos: nove ensaios sobre o filósofo frankfurtiano. Belo Horizonte: Ed. UFMG, 1997, p. 77.

${ }^{34}$ LOPEZ, Telê Ancona. Macunaima: a margem e o texto. São Paulo: HUCITEC, 1974, p. 90.

${ }^{35}$ Expressão de MAJOR NETO, Emílio José. A Lira Paulistana de Mário de Andrade: a insuficiência do Outro. 2006. Tese de doutoramento - Departamento de Teoria Literária e Literatura Comparada da FFLCH - USP.

${ }^{36}$ CHIAPPINI, Lígia. Macunaíma e o Retrato do Brasil. In: DECCA, Edgar S.; LEMAIRE, Ria. (Org.). Pelas margens: outros caminhos da história na literatura. Campinas: Ed. da Unicamp; Porto Alegre: Ed. da UFRGS, 2000, p. 310, 312. A autora demonstra, nesse ensaio, que "o projeto ideológico de Paulo Prado é aparentemente o mesmo de Mário de Andrade: apresentar uma visão do Brasil que desmistifique o nacionalismo ufanista, apontando os defeitos que escondia. A comparação 
projeto ideológico de Macunaíma, conectado a sua estrutura indeterminada, ele parece digerir com mais potencialidade a lição profunda de Adorno do que a do Retrato do Brasil, de Paulo Prado, a quem a rapsódia é dedicada. Supõem-se então que o movimento vertiginoso do livro é o que "impede Mário de utilizar os prefácios que havia escrito, porque eles reduziriam a algumas intenções o irredutível de Macunaíma".37

\section{Literatura e ensaio, particularidades}

"O ensaio como forma" do autor alemão recobriu nessa rápida discussão a experiência da carta, lugar de adestramento e amadurecimento do projeto nacionalista de Mário de Andrade formulado esteticamente em Macunaíma. Vimos que a convicção ensaística adorniana - "por assim dizer, metodicamente sem método" e aproximada de uma "autonomia artística" - revestiu também a experiência dos prefácios renegados da rapsódia. Mesmo tendo por foco os prefácios, a forma do ensaio deslizou para a forma de Macunaima. Temos que nos atentar, contudo, para o fato de que o nível de intencionalidade expressiva na narrativa modernista é altamente diverso ao das missivas e prefácios deixados à margem pelo autor. $\mathrm{E}$ é essa diferença que "Lukács não percebeu quando na carta a Leo Popper, que serve de introdução ao livro A alma e as formas, definiu o ensaio como uma forma artística", de acordo com Adorno.

Mesmo "irmã" da literatura, a forma do ensaio se diferencia da "arte tanto por seu meio específico, os conceitos, quanto por sua pretensão à verdade desprovida de aparência estética". ${ }^{38}$ Macunaíma, Retrato do Brasil, provido de aparência estética, é invenção e ensaio histórico sem implicar, porém, sobreposição do programa crítico ao trabalho artístico. ${ }^{39}$ A coerência entre esses dois polos, na obra, problematiza em grau máximo o conceito de nacionalismo, tecido anteriormente nas cartas-ensaio. Essa trajetória de tentativas e erros foi mediada,

dos dois livros deverá mostrar em que medida o projeto ideológico, em parte comum, é mais ou menos problematizado quando se faz na ficção ou no ensaio". Segundo a crítica se o projeto de Paulo Prado "já avança em relação ao nacionalismo exclamativo como em questionamento, em Macunaima, sobre esse questionamento acontece outro. [...]. Não há, em Macunaima, uma predominância da negação, como no Retrato... nem uma solução afirmativa em que se converte a negação. Na verdade, não há nem sim nem não, e há uma coexistência dos dois".

${ }^{37}$ Idem, ibidem, p. 313.

${ }^{38}$ A, p. 15 e 18.

${ }^{39} \mathrm{Na}$ esteira de Tristão de Ataíde, Augusto Frederico Schmidt e José Vieira, resenhistas da primeira onda da fortuna crítica de Macunaíma (1928-1936), entenderam "haver desequilíbrio entre ficção e ideia". O livro seria "mais obra de crítico", uma vez que "o trabalho de criação artística" fora em prol de um "programa nacionalista preestabelecido, fundamentado na pesquisa, à procura de uma expressão verdadeiramente nacional". Nota-se que os autores diluem o artístico/estético da obra de Mário de Andrade. Tese já citada de José de Paula Ramos Júnior (2006, p. 68). 
nessa discussão, pelos prefácios-ensaios cuja densidade está além das cartas e aquém de Macunaíma.

[Este trabalho, aqui revitalizado de mais leituras, foi originalmente elaborado para a disciplina "A epistolografia e o projeto pedagógico de Mário de Andrade", ministrada pelo Prof. Dr. Marcos Antonio de Moraes (DLCV-USP), no primeiro semestre de 2007. O artigo, na primeira versão, foi também apresentado e publicado nos anais do XI Encontro Regional da ABRALIC em julho de 2007, realizado na USP. ] 